\title{
Fetal akinesia-cerebral and retinal hemorrhage syndrome
}

INSERM

\section{Source}

INSERM. (1999). Orphanet: an online rare disease and orphan drug data base. Fetal akinesia-cerebral and retinal hemorrhage syndrome. ORPHA:363409

Fetal akinesia-cerebral and retinal hemorrhage syndrome is a rare, lethal, congenital myopathy syndrome characterized by decreased fetal movements and polyhydraminos in utero and the presence of akinesia, severe hypotonia with respiratory insufficiency, absent reflexes, joint contractures, skeletal abnormalities with thin ribs and bones, intracranial and retinal hemorrhages and decreased birth weight in the neonate. 